\title{
Pangolins in peril: using local hunters' knowledge to conserve elusive species in Vietnam
}

\author{
Peter Newton $^{1, *}$, Nguyen Van Thai ${ }^{2}$, Scott Roberton ${ }^{3}$, Diana Bell ${ }^{1}$ \\ ${ }^{1}$ Centre for Ecology, Evolution and Conservation, University of East Anglia, Norwich NR4 7TJ, UK \\ ${ }^{2}$ Carnivore and Pangolin Conservation Program, Cuc Phuong National Park, PO Box 179, GPO Ha Noi, Vietnam \\ ${ }^{3}$ Wildlife Conservation Society, Vietnam Hunting and Wildlife Trade Program, PO Box 179, GPO Ha Noi, Vietnam
}

\begin{abstract}
Pangolins are among the most valuable and widely traded taxa in the Southeast Asian illegal wildlife trade, yet little is known of their ecology and they are rarely reported in biodiversity surveys. Firstly, this study collated field and museum reports to produce the first distribution maps for the pangolins Manis pentadactyla and M. javanica in Vietnam. We also demonstrated that current biodiversity monitoring methods are rarely successful in recording pangolin presence and that most of the information about their distribution derives from the knowledge of local hunters. Secondly, semi-structured interviews with hunters revealed that the methods used to catch pangolins differed depending on species and site and suggest that the more terrestrial populations of $M$. pentadactyla are at greater risk from hunting than the more arboreal M. javanica. We highlight the value of applying local hunters' knowledge to developing ecological study methods and conservation programmes for pangolin species in Southeast Asia.
\end{abstract}

KEY WORDS: Pangolin $\cdot$ Wildlife trade $\cdot$ Conservation $\cdot$ Hunter $\cdot$ Interview $\cdot$ Vietnam Resale or republication not permitted without written consent of the publisher

\section{INTRODUCTION}

Intense hunting to supply the illegal wildlife trade has severely depleted the biodiversity of Asian tropical forests (Bennett et al. 2002, Fa et al. 2002). Although people have hunted mammals in these habitats for thousands of years, regional declines in most species have occurred largely within the last half century (Corlett 2007). As the market value of wildlife has escalated with increasing demand and decreasing supply, hunting purely for trade has eclipsed hunting primarily for subsistence (Roberton et al. 2004, Sterling et al. 2006).

Over the past 2 decades, Vietnam has become an important link in the international wildlife trade network, acting as a conduit for exports from other Southeast Asian countries, such as Lao PDR, Cambodia and Myanmar, to international markets in Asia, Europe and America (Compton \& Le 1998, Bell et al. 2004). Mammal populations considered at greatest risk as a result of over-hunting include primates, bears, cats, civets, Asian elephants, wild cattle, deer and pangolins (Roberton et al. 2004, Anonymous 2005).
Pangolins (Order: Pholidota; Manis spp.) are insectivorous mammals confined to the Afrotropical and Indomalayan regions, with 8 extant species recognised (Corbet \& Hill 1992, Gaubert \& Antunes 2005). With the exception of $M$. culionensis, all 4 Asiatic pangolin species are classified as 'lower risk: near threatened' by the International Union for Conservation of Nature (IUCN 2007) and appear in Appendix 2 of the Convention on International Trade in Endangered Species of Wild Fauna and Flora, with a zero annual export quota for wild caught individuals or those traded for commercial purposes (CITES 2007).

Despite this protection, Asian pangolins are traded widely, being highly valued for their meat, which is considered a delicacy in China and Vietnam, their scales, which are used for traditional medicine by a number of Asian communities, and their thick skins, which were exported to international markets in Europe for many years to be made into belts, bags and shoes (Duckworth et al. 1999, Baltzer et al. 2001, Ellis 2005). Additional anthropogenic pressure results from the large-scale, rapid loss of their forest habitat (CEPF 
2005). Consequently, pangolins are considered by many to be among the most threatened species of mammal in Asia (Davies 2005), and a recent IUCN/SSC Global Mammal Assessment (GMA) workshop proposed that the 3 near-threatened species be upgraded to endangered (M. Hoffman pers. comm.).

Very few studies have examined wild populations of Asiatic species (e.g. Wu et al. 2003, Lim \& Ng 2007). Consequently, insufficient data are available on pangolin distribution and population status to enable an assessment of their conservation needs. One of the major impediments to studying wild pangolins has been the difficulty in locating them. In many areas where biodiversity surveys have been conducted, no pangolins were recorded, despite extensive nocturnal searches (Duckworth et al. 1999). The potential for radio-tracking wild-caught pangolins to monitor home-range size and habitat utilisation has been demonstrated (Heath \& Coulson 1997a,b, Lim \& Ng 2007), but these studies have been conducted in areas with high pangolin densities. Field detection and monitoring methodologies applicable to areas with heavily depleted populations, and thus of more relevance across the natural range of Asian pangolins, are urgently required.

This study examined the hypothesis that current standard ecological monitoring techniques are not well suited to the detection and surveying of populations of the Asian pangolins Manis pentadactyla and M. javanica. The continued presence of pangolins in confiscations made by forest rangers indicates that hunters continue to extract large numbers of pangolins annually from the wild and possess the knowledge and techniques to locate pangolins. A greater understanding of these hunting practices may guide future studies of pangolin ecology and assist the development of a field detection methodology for monitoring populations of $M$. pentadactyla and $M$. javanica.

\section{MATERIALS AND METHODS}

Systematic review of biodiversity surveys. Field records of Manis pentadactyla and M. javanica were collected systematically from literature reports of non-governmental conservation organisations (NGOs) currently working in Vietnam. Records were also sourced from published literature and from reliable, unpublished observations. The study was focussed on Vietnam, but records were additionally collated from a number of other Southeast Asian countries whenever possible.

All available field records were compiled into a database using the following categories: species, location of record (province, district, commune and protected area), geographic coordinates, record type (obser- vation, camera trap, field signs, specimen, interview or literature review) and survey date. Altitude (in metres) and forest/habitat type were recorded when available. Field records from observations by reliable observers, camera traps, tracks and signs (which are considered easily identifiable for pangolin species) and specimens found in the field were classed as 'confirmed records', whilst interview reports, specimens in hunters' homes and confiscated animals were classed as 'unconfirmed reports'. All methods employed in each survey were recorded, whether successful in recording pangolin presence or not.

Both confirmed records and unconfirmed reports for each species were incorporated into a geographic information system (GIS) layer using ArcMap (Ver. 9.1). The majority of reports lacked precise map coordinates, so location was plotted at a central point within the area identified (e.g. commune or protected area level).

Annual biodiversity survey effort was measured as the number of surveys assessing the diversity of mammals within an area of mapped pangolin distribution carried out within a particular year. For this analysis the 2 pangolin species were considered together, since a large number of records reported 'Manis spp.' rather than identifying an individual to species level. Survey effort was plotted against year, with the date of the survey defined as the end of the field work period. Surveys from 2005 and 2006 were excluded from the analysis, since the delay in publications becoming available means that these years had apparently low survey effort (mean lag time from end of survey to publication $=9 \mathrm{mo}, \mathrm{n}=90$ ).

Field surveys were identified that listed all methodologies employed to assess the biodiversity of a particular site. All surveys that recorded the presence of one or more pangolin species, and which reported the method employed, were used to assess the relative success of alternative biodiversity monitoring methodologies. These methods included standard ecological methods (line-transects and field sightings, records of tracks and signs, camera traps) and secondary data methods (interviews with hunters, specimens found in villagers' homes). All field sightings were grouped together, since many surveys did not differentiate diurnal or nocturnal records. Surveys that failed to record pangolin presence by any method were excluded, since pangolins may not have been present in the actual study site.

Chi-squared analyses were used to test for associations between alternative survey methods and their success in recording pangolin presence. Again, since identification to species level was not necessarily reliable, the genus, which is unmistakable, was considered collectively. 
Hunter interviews. Hunters living in villages around protected areas in northern and central Vietnam were interviewed between April and June 2007. Three study sites were sampled, each within the known range of one or both species of pangolin: Cuc Phuong National Park (20.14 ${ }^{\circ}$ to $20.24^{\circ} \mathrm{N}, 105.29^{\circ}$ to $\left.105.44^{\circ} \mathrm{E}\right)(\mathrm{CPNP})$; the contiguous area comprising Ke Go Nature Reserve $\left(18.00^{\circ}\right.$ to $18.15^{\circ} \mathrm{N}, 105.83^{\circ}$ to $\left.106.12^{\circ} \mathrm{E}\right)$ and Khe Net State Forest Enterprise (a proposed nature reserve) $\left(18.02^{\circ} \mathrm{N}, 105.58^{\circ} \mathrm{E}\right)(\mathrm{KGKN})$; and Song Thanh Nature Reserve $\left(15.13^{\circ}\right.$ to $15.41^{\circ} \mathrm{N}, 107.21^{\circ}$ to $\left.107.50^{\circ} \mathrm{E}\right)$ (STNR) (Fig. 1). Recent IUCN maps from the GMA suggest that CPNP is within the range of Manis pentadactyla, that STNR is within the range of $M$. javanica and that KGKN is within the range of both species (M. Hoffman pers. comm.). These sites therefore offered the opportunity to examine hunting practices in areas in which each species lived independently and in one area where they were believed to co-exist.

Hunters living in the proximity of the 3 sites were interviewed and data collected on their knowledge of pangolin ecology, historic and contemporary pangolin hunting practices, and the dynamics of the trade in pangolins. Potential interviewees were identified on the basis of their reputation as hunters knowledgeable about pangolins, with a respondent-driven sampling method, as previous interviewees inferred or named experienced pangolin hunters in neighbouring villages or communes (Salganik \& Heckathorn 2004). Interviewees were selected according to their availability and willingness to participate in an informal interview. Since it is illegal to hunt in protected areas or to trade a pangolin without a permit, the issues discussed were extremely sensitive and complete random sampling within the hunter population was not possible. This selection method was a feasible and realistic surrogate given the restrictions of time and the sensitive nature of the study topic.

Semi-structured interviews were conducted by a 2person team, working within the guidance of an interview framework (Huntington 2000), but without precise, pre-determined questions so that interesting lines of discussion could be pursued (Bernard 2000). Open questioning was employed wherever possible, to avoid leading the interviewee into an answer. All dialogue was recorded by one of the interviewers and uncertainties were clarified immediately after the interview.

Interviews varied in content, length and interviewee attitude and knowledge, and there was often an almost unlimited number of possible responses to a given question. Response frequencies are therefore presented in the results as percentages in the format $x \%(y / z)$, where $y$ is the number of interviewees that gave a particular response and $z$ is the total number of interviewees that were asked the question, including those that gave an alternative answer or were unable to provide an answer.

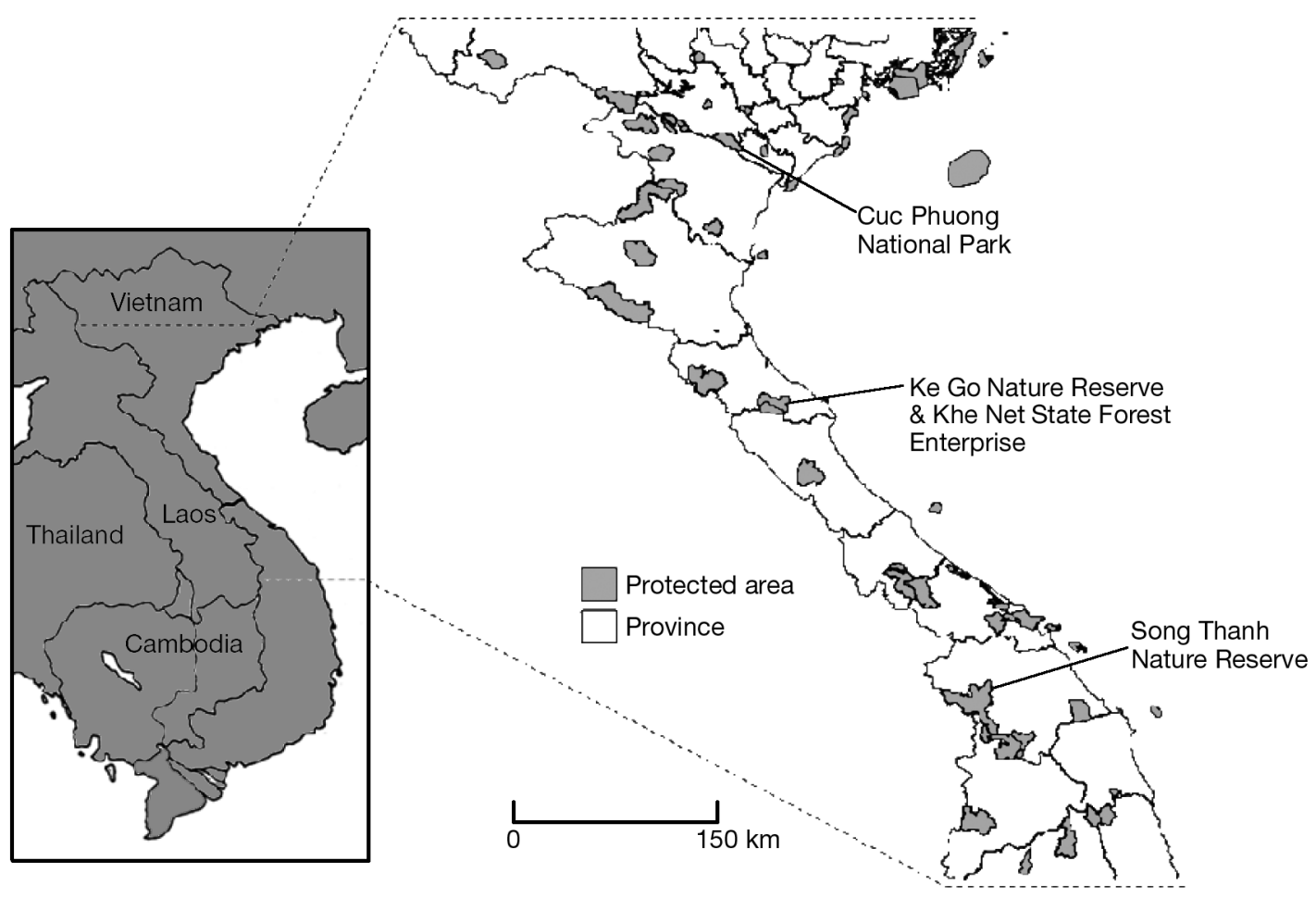

Fig. 1. Location of study sites for semi-structured interviews with pangolin hunters 
It was possible to infer the relative extent to which an individual hunter used a particular hunting method from each interview and to categorise each method according to whether that hunter had used it predominantly, frequently, rarely or never to catch pangolins. Log-linear analyses were used to test for differences in hunting method use between species and between study sites. Fisher's exact test was used to test $2 \times 2$ contingency associations.

A general linear model was used to test for a change in the reported price of pangolin per kg since 1990. Reported values were adjusted to 1990 prices to account for annual inflation rates, which were conservatively taken to be $10 \%$ from 1990 to 1997 (UNICEF 2007) and $4 \%$ from 1997 to 2007, except 1998, which was $9.2 \%$ (U.S. Department of State 2007).

\section{RESULTS}

\section{Biodiversity surveys}

A total of 196 field records of Manis pentadactyla and $M$. javanica were compiled from biodiversity surveys. The plot of these field records indicates that the 2 species have differing geographic distributions within Vietnam, with a clear latitudinal separation (Fig. 2). Confirmed records were limited in number for both species (Table 1), but those for $M$. pentadactyla were from northern provinces whilst those for $M$. javanica were predominantly from southern provinces. There is

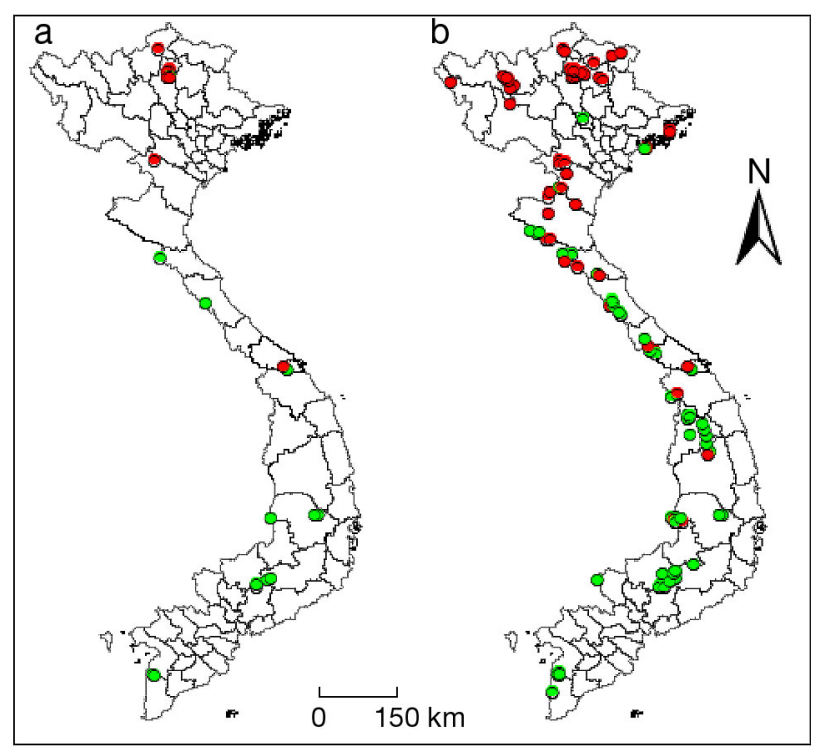

Fig. 2. Manis pentadactyla and M. javanica. (a) Confirmed field records and (b) all field records (both confirmed and unconfirmed) of $M$. pentadactyla (red dots) and $M$. javanica (green dots) in Vietnam a region of overlap of the 2 species in the central provinces between Da Nang and Ha Tinh (most southerly confirmed record of $M$. pentadactyla = $16.0^{\circ} \mathrm{N}$; most northerly confirmed record of $M$. javanica $=18.5^{\circ} \mathrm{N}$ ). Unconfirmed records showed the same trend, although the north/south separation was less distinct.

Annual biodiversity survey effort increased significantly during the period 1989 to 2004 ( $\mathrm{r}=0.67, \mathrm{p}=$ $0.005)$, as did the number of confirmed records per survey of the species Manis pentadactyla and M. javanica (Fig. 3).

A minority of records $(17 \%, 34 / 196)$ of the 2 species were confirmed records from standard ecological survey techniques (i.e. line transects, detection of tracks and signs and camera-trapping). Most were unconfirmed reports $(83 \%, 162 / 196)$ from methods which drew upon the knowledge of local people (i.e. interviews and examining specimens in hunters' houses). There was a significant association between the different methods used and the relative frequency with which they recorded pangolin presence, with interviews being the most frequent method $\left(\chi^{2}=75.35, \mathrm{df}=4, \mathrm{p}<0.001\right)$ (Fig. 4).

Of the 34 records obtained from the 3 ecological survey methods, there was a significant association between the method used and the species recorded $\left(\chi^{2}=18.68, \mathrm{df}=2, p<0.001\right)$. Manis pentadactyla were recorded significantly more frequently from signs of their presence (e.g. diggings and spoor) (9/10, 90\%), whilst $M$. javanica were recorded significantly more frequently from sightings $(10 / 21,48 \%)$ and cameratrap records $(8 / 21,38 \%)$.

Camera-trap data from surveys within the range of one or both pangolin species illustrate the extent to which pangolins are recorded by this method (Table 2). Four of the 12 surveys reviewed recorded photographs of pangolins, with a total of 8 photographs resulting from more than 14000 trap nights and 2600 animal photographs.

\section{Hunter interviews}

Interviews were conducted with a total of 84 hunters (CPNP: 34, KGKN: 24, and STNR: 26) in 41 villages and lasted between 35 and $170 \mathrm{~min}$ (mean = $90 \mathrm{~min}$, $\mathrm{n}=84$ ). Interviewees were all males, aged between 22 and $70(46.02 \pm 1.09$, mean $\pm \mathrm{SE}, \mathrm{n}=84)$. All had caught a pangolin on at least 1 occasion, though most reported many years of experience.

All hunters interviewed in the CPNP area (31/31) reported that only 1 species of pangolin is found in the National Park, with all respondents (11/11) identifying, from photographs, the species present as being Manis pentadactyla. 
Table 1. Manis pentadactyla and M. javanica. Confirmed field records in Southeast Asian countries. NBCA: National Biodiversity Conservation Area

\begin{tabular}{|c|c|c|c|c|c|}
\hline Source & $\begin{array}{l}\text { Survey } \\
\text { year }\end{array}$ & Country & Survey area & $\begin{array}{l}\text { Field record information } \\
\text { source }\end{array}$ & Species \\
\hline Emmett \& Olsson (2005) & 2004 & Cambodia & Central Cardamom Mountains & Camera trap (2 photos) & M. javanica \\
\hline Neath \& Setha (2001) & 2000 & Cambodia & Bokor National Park & Camera trap (4 photos) & M. javanica \\
\hline Lynam et al. (2006) & 2002 & Thailand & Khao Yai National Park & Camera trap & M. javanica \\
\hline Timmins \& Cuong (1999) & 1999 & Vietnam & Huong Son Annamite Forest & Camera trap & M. javanica \\
\hline Neath \& Setha (2001) & 2000 & Cambodia & Bokor National Park & Sighting & M. javanica \\
\hline Kong \& Tan (2002) & 2002 & Cambodia & Kirirom National Park & Sighting & M. javanica \\
\hline WCS (1995) & 1995 & Lao PDR & Adjacent to Nam Kading NBCA & Sighting & M. javanica \\
\hline Care (2004) & 2004 & Vietnam & U Minh Thuong National Park & Sighting & M. javanica \\
\hline Murphy \& Phan (2001) & 2001 & Vietnam & Cat Tien National Park & Sighting (2 records) & M. javanica \\
\hline Le et al. (1997a) & 1997 & Vietnam & Phong Nha-Ke Bang National Park & Sighting & M. javanica \\
\hline Le et al. (1997b) & 1997 & Vietnam & Ea So & Sighting (2 records) & M. javanica \\
\hline Dang et al. (1995) & 1995 & Vietnam & Yok Don National Park & Sighting & M. javanica \\
\hline Frontier Vietnam (1994) & 1994 & Vietnam & Ba Na Nature Reserve & Sighting & M. pentadactyla \\
\hline Vu et al. (2005) & 2005 & Vietnam & Lung Day, Cao Bang province & Freshly dug burrow & M. pentadactyla \\
\hline BirdLife (2004) & 2004 & Vietnam & Yok Don National Park & Freshly dug burrow & M. javanica \\
\hline Le et al. (2004) & 2003 & Vietnam & Na Hang Nature Reserve & Freshly dug burrow (2 records) & M. pentadactyla \\
\hline BirdLife (2003) & 2002 & Vietnam & Na Hang Nature Reserve & Freshly dug burrow & M. pentadactyla \\
\hline Long \& Tuoc (1999) & 1999 & Vietnam & Pu Mat Nature Reserve & Freshly dug burrow & Manis spp. \\
\hline Round (1999) & 1999 & Vietnam & Pu Mat Nature Reserve & Freshly dug burrow & Manis spp. \\
\hline Walston et al. (2001) & 2001 & Cambodia & Mondulkiri province & Tracks or signs & M. javanica \\
\hline WCS (1995) & 1995 & Lao PDR & Adjacent to Nam Kading NBCA & Tracks or signs & Manis spp. \\
\hline FFI (2006) & 2006 & Vietnam & Khau Ca area & Tracks or signs & M. pentadactyla \\
\hline Dang et al. (2004) & 2003 & Vietnam & Da Teh State Forest Enterprise & Tracks or signs & M. javanica \\
\hline FFI (2005) & 2003 & Vietnam & Pu Luong Nature Reserve & Tracks or signs & M. pentadactyla \\
\hline Frontier Vietnam (1996) & 1996 & Vietnam & Na Hang Nature Reserve & Tracks or signs (3 records) & M. pentadactyla \\
\hline
\end{tabular}

All hunters interviewed in the KGKN area (24/24) reported that 2 different species of pangolin occur in the region. They identified Manis pentadactyla as one of these species, again from photographs, referring to it as the 'buffalo pangolin' $(83 \%, 20 / 24)$ or 'black pangolin' $(17 \%, 4 / 24)$. They identified $M$. javanica as the other species, most commonly calling it the 'rice pangolin' $(83 \%, 20 / 24)$. However, $50 \%$, (12/24) described

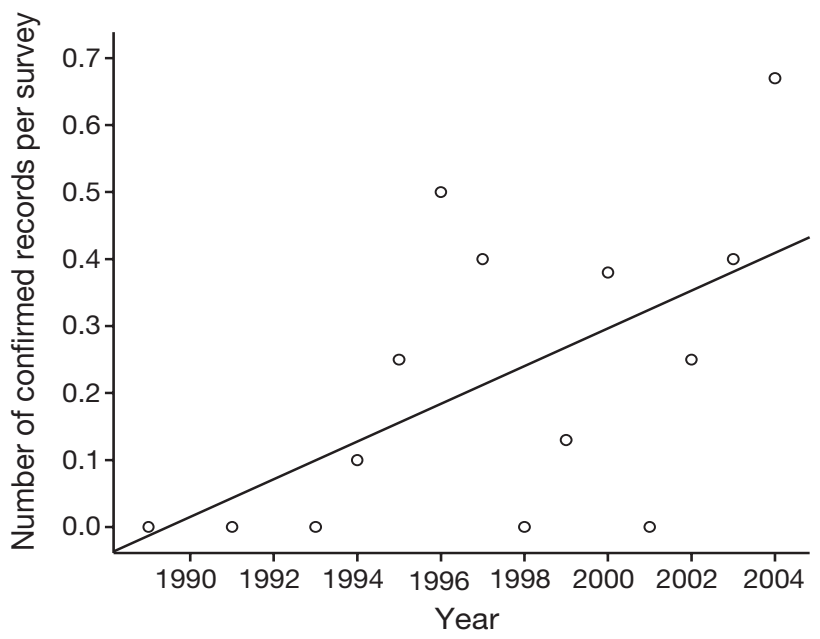

Fig. 3. Manis pentadactyla and M. javanica. Change in the number of confirmed field records of pangolins per biodiversity survey between 1989 and $2004(\mathrm{r}=0.58, \mathrm{p}=0.03, \mathrm{n}=14)$ this second species as 2 distinct 'types,' with the second type referred to as the 'cow pangolin' $(67 \%, 8 / 12)$.

Almost all hunters interviewed in the STNR area reported just 1 species, Manis javanica (96\%, 25/26), but also distinguished 2 types, referring to them most commonly as the 'large pangolin' $(88 \%, 14 / 16)$ and 'small pangolin' (87\%, 13/15).

Hunters reported that populations of both species of pangolin have been reduced $(95 \%, 93 / 98)$ and all respondents believe that this is predominantly a consequence of hunting pressure (55/55). However, some hunters in CPNP also attributed the decline to forest loss $(27 \%, 6 / 28)$. All respondents in KGKN, which

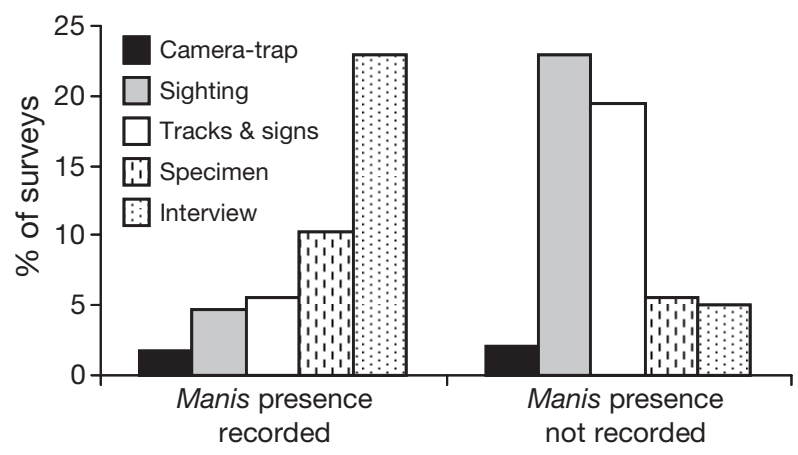

Fig. 4. Manis spp. Relative success of different biodiversity survey methodologies at recording pangolin presence 


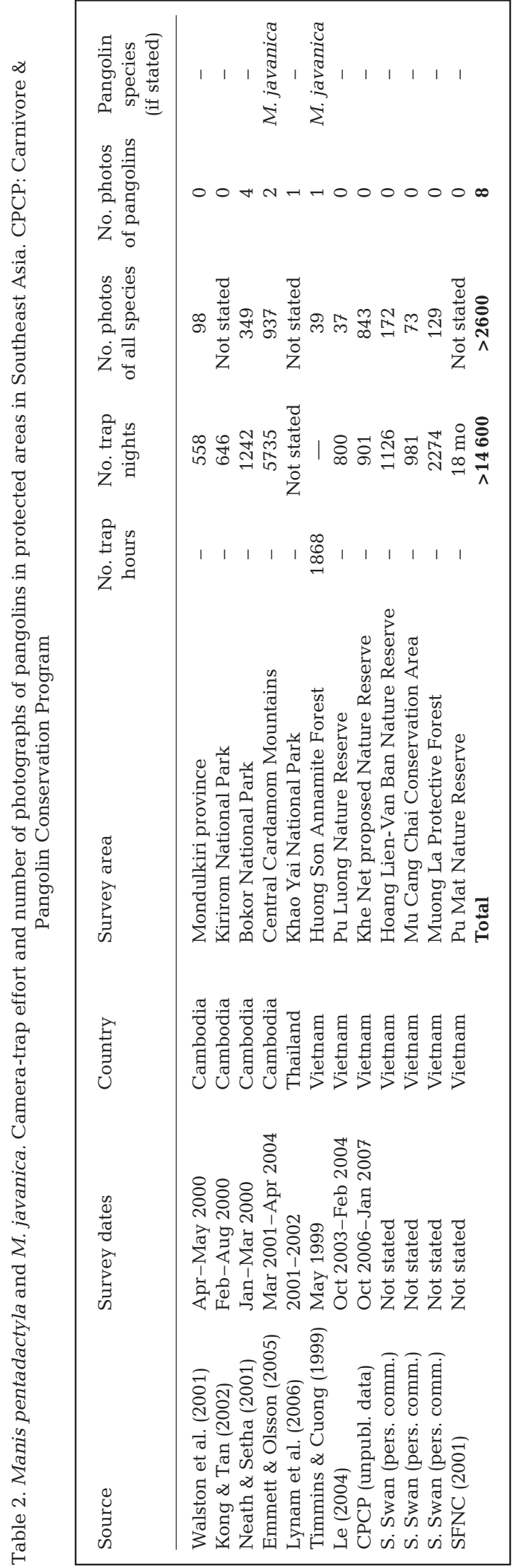

incorporates the range of both pangolin species, believed that there are fewer Manis pentadactyla remaining in the forests than there are $M$. javanica $(20 / 20)$, with some hunters believing that M. pentadactyla is now locally extinct $(38 \%, 9 / 24)$.

All respondents in the CPNP and KGKN areas said that Manis pentadactyla sleep mainly in soil burrows (53/53) and that their diet constitutes either solely termites $(78 \%, 45 / 58)$ or ants and termites $(18 \%, 10 / 55)$. None of the hunters questioned believed that $M$. pentadactyla climbs regularly, stating that the species never climbs $(79 \%, 37 / 47)$, rarely climbs $(13 \%, 6 / 47)$ or only climbs 1 or $2 \mathrm{~m}$ from the ground $(8 \%, 4 / 47)$. This contrasted with hunters questioned about $M$. javanica, who all stated that the species regularly climbs (50/50). M. javanica were reported to sleep predominantly in hollow trees $(94 \%, 47 / 50)$ or in holes beneath the tree trunk $(74 \%, 37 / 50)$ and to feed mainly on ants and termites $(61 \%, 30 / 49)$, solely on termites $(22 \%, 11 / 49)$ or solely on ants $(16 \%, 8 / 49)$.

\section{Hunting practices}

A number of alternative means of catching pangolins were described by hunters in the 3 study sites. The following 6 methods were the most commonly reported.

Trained dogs. Many hunters reported currently or previously using dogs to hunt pangolins. The majority reported they would take their dog to the forest primarily in the daytime $(93 \%, 41 / 44)$. Most stated that their dog was capable of following the scent of a pangolin to its resting place $(86 \%, 43 / 50)$, though some said that it could only confirm by smell that a pangolin was actually in a tree hole or burrow found by the hunter $(12 \%, 6 / 50)$. The majority of respondents stated that they would catch more pangolins with a dog in the rainy season $(66 \%, 19 / 29)$, but a number stated that they could use the dog at any time of year $(28 \%, 8 / 29)$. Dogs were generally reported not to specialise in pangolins $(78 \%, 25 / 32)$, but to be also trained to hunt other species including turtles, wild pigs and muntjac.

Tracking. Hunters reported a range of alternative field signs which would indicate a pangolin's recent presence in an area and which might also assist them in locating the animal (Table 3). In particular, many respondents in all 3 areas claimed to be able to both recognise and to estimate the approximate age of a pangolin burrow based upon certain burrow characteristics and signs, including the colour and dampness of soil at the entrance, and the presence of leaves or spiders webs in the entrance. All hunters that were asked whether there was a more favourable season for tracking pangolins reported that the rainy season was the easiest time of year to find both species (30/30). 
Table 3. Manis pentadactyla and M. javanica. Field signs used to infer the recent activity of pangolins by hunters living around Cuc Phuong National Park (CPNP) and Song Thanh Nature Reserve (STNR). Information given by hunters in Ke Go Nature Reserve and Khe Net State Forest Enterprise (KGKN) is not included, since responses were confused by the presence of both species. 'Soil' refers to soil clinging to a pangolin's body after digging, which brushes off onto vegetation and trees as it walks

\begin{tabular}{|c|c|c|c|}
\hline Species & Field sign & $\begin{array}{l}\text { Jumber of hunters that } \\
\text { reported seeing sign }\end{array}$ & Comments \\
\hline \multirow[t]{6}{*}{ M. pentadactyla } & & 34 & $\begin{array}{l}\text { Total no. of interviewees in CPNP reporting finding } \\
\text { M. pentadactyla by tracking }\end{array}$ \\
\hline & Diggings (feeding) & 24 & \\
\hline & Spoor & 17 & $\begin{array}{l}11 \text { stated that they only see spoor at the entrance to } \\
\text { burrows }\end{array}$ \\
\hline & Soil & 16 & $\begin{array}{l}7 \text { stated that it is difficult to use this sign to locate } \\
\text { pangolins }\end{array}$ \\
\hline & Faeces & 6 & All stated that faeces are only found in or at a burrow \\
\hline & Claw marks (on tree) & 1 & \\
\hline \multirow[t]{6}{*}{ M. javanica } & & 19 & $\begin{array}{l}\text { Total no. of interviewees in STNR reporting finding } \\
\text { M. javanica by tracking }\end{array}$ \\
\hline & Diggings (feeding) & 10 & \\
\hline & Spoor & 2 & \\
\hline & Soil & 11 & \\
\hline & Faeces & 0 & \\
\hline & Claw marks (on tree) & 12 & $\begin{array}{l}6 \text { stated that they can distinguish recent marks, most } \\
\text { commonly from the presence of sap }\end{array}$ \\
\hline
\end{tabular}

Hunters in all areas stated that Manis pentadactyla found in burrows were usually captured by digging them out of the burrow $(90 \%, 46 / 51)$, or by setting a trap or net and waiting for the animal to emerge $(10 \%$, 5/51). M. javanica found using dogs are usually captured by cutting down the tree in which they are resting $(98 \%, 45 / 46)$.

Pangolin-specific traps. Hunters reported using traps set specifically to catch pangolins. These are set either at burrows or entrances to tree hollows which are known to have been used by a pangolin in the past to catch the animal when it returns $(86 \%, 19 / 22)$ or in areas where there are signs (e.g. diggings, tracks) that pangolins have been feeding $(14 \%, 3 / 22)$. Of those hunters that used this method, as either a primary or secondary means of catching either species, all 27 in KGKN and STNR set snare traps, whilst the 4 hunters using traps in CPNP all used metal, pressuretriggered clamp traps instead. Snare traps are made from bicycle brake cable (14/14), and an equal number of hunters reported using 'lying' snares (horizontal traps to catch the animal's foot; 14/28) and 'standing' snares (vertical traps to catch the animal's neck, body or tail; 14/28).

Non-selective traps. Hunters also reported using traps opportunistically placed in the forest. These traps are placed in long lines in the forest $(97 \%, 29 / 30)$, usually in conjunction with a drift fence (10/10), to guide passing animals of any species into the trap. Of those hunters using this method, all used snare traps (44/44), with approximately equal utilisation of lying (47\%, $17 / 36)$ and standing $(53 \%, 19 / 36)$ snares.
Spotlighting. Of the 38 hunters who claimed to have caught one or both pangolin species at night using a spotlight, none were specifically searching for pangolins and most $(61 \%, 23 / 38)$ stated that they were primarily searching for other species, including frogs, geckos and civets. Sixty-eight percent (21/31) of respondents said that pangolin eyes do not reflect the light from a torch (this is also supported by trials of pangolins in captivity in the Carnivore \& Pangolin Conservation Program in Cuc Phuong National Park) and that they had either seen the body outline of the pangolin $(57 \%, 12 / 21)$ or heard it moving $(14 \%, 3 / 21)$.

Opportunistic encounters. Hunters reported occasionally catching pangolins whilst engaged in nonhunting activities. Individuals reported finding pangolins inside trees when cutting them down for firewood, or seeing them whilst in the forest or on agricultural land bordering forest areas.

The 4 methods predominantly used to hunt pangolins were significantly associated with both the species and the study site. A 3-way log-linear analysis of species, study site and hunting method produced a final model retaining all 2-way interactions (likelihood ratio: $\chi^{2}=$ $0.48, \mathrm{df}=6, \mathrm{p}=1.00)$. The 2 species are mainly hunted using different methods $\left(\chi^{2}=32.31, \mathrm{df}=6, \mathrm{p}<0.001\right)$ and different methods are used to varying extents in the 3 study sites $\left(\chi^{2}=11.11, \mathrm{df}=3, \mathrm{p}<0.011\right)$. The data presented in Fig. 5 shows that Manis pentadactyla is primarily located by tracking in CPNP, that both species are predominantly hunted using dogs in KGKN and that $M$. javanica are mainly caught by hunters setting traps (both pangolin-specific and non-selective) in STNR. There 


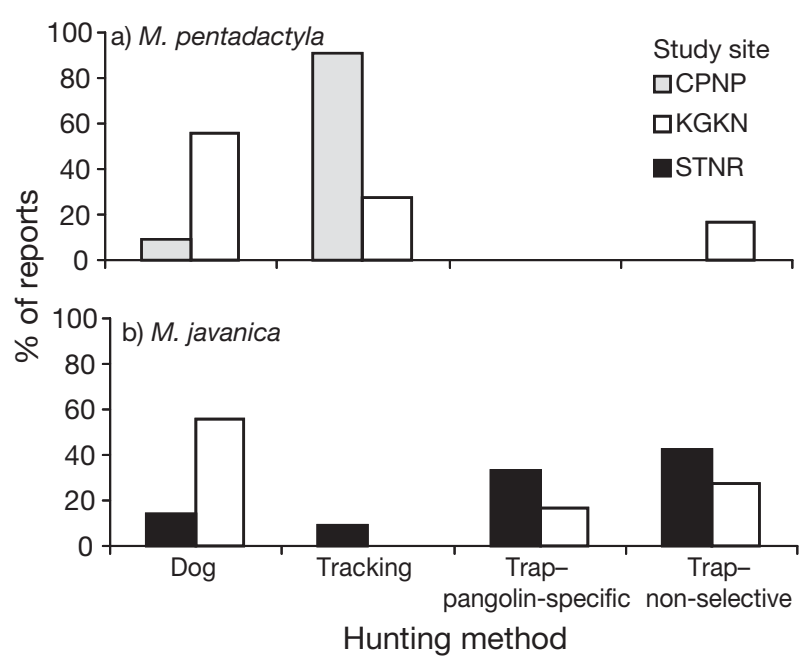

Fig. 5. Manis pentadactyla and M. javanica. Frequency of reports of methods used as the predominant means to hunt (a) M. pentadactyla and (b) M. javanica in the 3 study sites: Cuc Phuong National Park (CPNP); Ke Go Nature Reserve and Khe Net State Forest Enterprise (KGKN); Song Thanh Nature Reserve (STNR)

were also significant associations between the study site and methods used frequently, (log-linear analysis: $\chi^{2}=$ 22.66, $\mathrm{df}=10, \mathrm{p}=0.012$ ), and between species and methods used rarely $\left(\chi^{2}=17.62, \mathrm{df}=5, \mathrm{p}=0.003\right)$.

The use of hunting dogs to catch pangolins has declined, with significantly more hunters reporting that they previously hunted with a dog than reporting currently using one (previously: $55 \%$ [46/84], now: $19 \%[16 / 84]_{i}$ Fisher's exact test, $\left.p<0.001\right)$. The main reasons cited for this decline were: in CPNP, the risk of being caught by rangers $(4 / 5)$; in KGKN, the difficulty in training dogs when there are few pangolins or experienced dogs to learn from (9/15); and in STNR the risk of dogs being injured in snare traps (5/12).

All respondents living in the KGKN area, who have had the opportunity to hunt both pangolin species, stated that Manis pentadactyla was easier to hunt than M. javanica $(22 / 22)$, both by tracking (17/17) and with dogs (17/17). They explained that this is because, firstly, $M$. pentadactyla burrows are easier for a hunter to see $(76 \%, 17 / 22)$ and, secondly, because it is more difficult for a dog to follow the scent of M. javanica, which is partially arboreal $(76 \%, 17 / 22)$. All explanations of this apparent distinction in the ease of hunting alluded to the more terrestrial behaviour of $M$. pentadactyla and the more arboreal behaviour of $M$. javanica (31/31).

\section{Trade}

Both species of pangolin are currently hunted solely for the wildlife trade, with $99 \%$ of respondents $(80 / 81)$ stating that all pangolins caught are now sold to traders. However, this represents a switch from subsistence hunting to commercial trade, since hunters reported that captured pangolins had formerly been consumed locally $(93 \%, 78 / 84)$, primarily for their meat $(94 \%, 79 / 84)$.

The price paid to hunters per $\mathrm{kg}$ of pangolin has increased at a rate more rapid than annual inflation since the commercial trade in the species began (Fig. 6). All interviewees questioned stated that the price is not stable but tends to fluctuate throughout the year $(8 / 8)$ and that pangolins with an injury are less valuable (28/28). Injured pangolins are reportedly reduced from a mean minimum of $16 \%$ of their value $(\mathrm{n}=9)$, to a mean maximum of $39 \%(\mathrm{n}=25)$. Most hunters questioned stated that they received a lower price per $\mathrm{kg}$ for a larger pangolin than for a smaller one $(87 \%, 20 / 23)$, all agreeing that pangolins over $5 \mathrm{~kg}$ are less valuable (mean maximum weight for optimal price $=4.4 \mathrm{~kg}$, mean minimum $=0.7 \mathrm{~kg}, \mathrm{n}=20$ ).

\section{DISCUSSION}

This study has compiled the first range distribution maps for the 2 pangolin species, Manis pentadactyla and M. javanica, in Vietnam. The lack of confirmed field records from standard ecological survey methods has been demonstrated, highlighting the need for taxon-specific field detection techniques. Hunters reported that the 2 species of pangolin are caught using different hunting methods and that there is also inter-site variation in the predominant technique used. The research reveals that the threat to both species persists, but that populations of $M$. pentadactyla

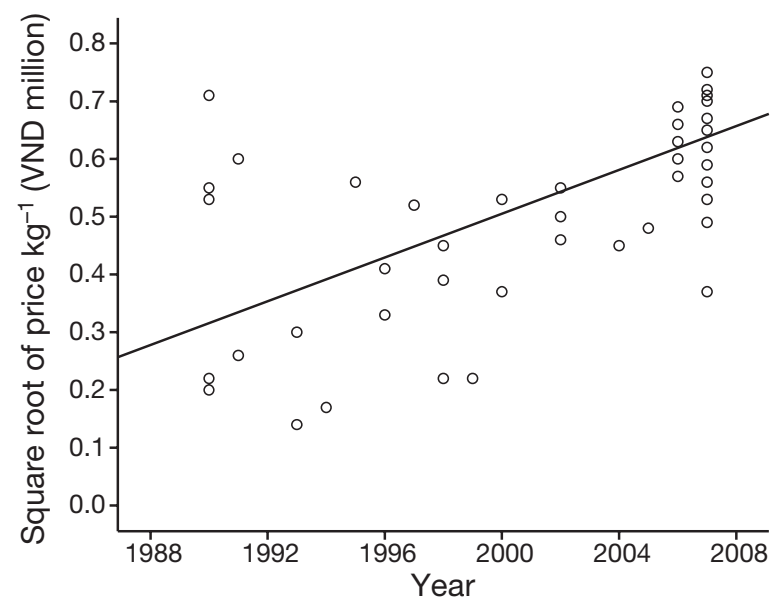

Fig. 6. Manis spp. Price trend for commercial sales of pangolin in Vietnam since 1990. Square root price $=0.316+(0.019 \times \mathrm{yr})$, $F_{1,91}=88.08, \mathrm{R}^{2}=0.49, \mathrm{p}<0.001$. Values adjusted to 1990 prices to account for inflation rates. VND: Vietnamese dong 
appear to have suffered a greater decline because this species is more easily captured. These findings contrast with descriptions by previous authors, who have not reported ecological differences between different pangolin species (e.g. Sterling et al. 2006). The results of this study highlight measures which may help to conserve $M$. pentadactyla and $M$. javanica in Vietnam's protected areas and suggest techniques which may facilitate future studies of pangolin ecology.

\section{Biodiversity surveys}

This study produced distribution maps for the 2 species of pangolin occurring in Vietnam. Although data on the abundance of pangolin species were extremely sparse, distribution mapping may help to target conservation efforts and to identify sites for future field research or placement of confiscated individuals. Similar field record compilations have been made for small carnivores and primates in Vietnam, and have guided conservation prioritisation for these taxa (Geissmann et al. 2000, Nadler et al. 2003, Roberton 2007).

The confirmed records showed a clear latitudinal separation in the ranges of Manis pentadactyla and $M$. javanica in Vietnam, with a central region of distribution overlap. The latitudinal separation of unconfirmed records was less distinct, probably due to a greater likelihood of species misidentification during interviews.

The region of distribution overlap of the 2 species suggests that a simple latitudinal replacement, as mapped by Corbet \& Hill (1992), may be an oversimplistic interpretation of pangolin distribution in Vietnam. We were unable to test the suggestion of Duckworth et al. (1999) that an altitudinal separation of the 2 species may occur, due to the low number of confirmed field records reporting elevation (2/34) or accurate location coordinates (7/34). Similarly, no conclusions could be drawn concerning habitat preferences of either species, due to the low reporting of forest type $(5 / 34)$ or elevation in the confirmed field records. This review has therefore highlighted a need for more detailed data collection in biodiversity surveys, all of which should provide basic data on geographical coordinates, vegetation type and elevation for confirmed records.

Biodiversity survey effort in Southeast Asia has increased in the last 2 decades. Vietnam implemented its 'open-door' policies in the early 1990s and since then an increasing number of international organisations have been conducting biodiversity surveys and scientific training of field biologists and students throughout the country. This has been matched by an increased number of confirmed records of pangolin species recorded per survey, which may suggest either increased proficiency of survey teams in identifying pangolin presence and/or better reporting of incidental mammal records during surveys targeting other species.

Field records from primary data sources remain relatively scarce, however, and we demonstrated a greater dependence on interview reports from local communities and hunters to identify pangolin distribution. This supports the observation that pangolins have not been well reported by biodiversity surveys (Duckworth et al. 1999) and underlines the need to develop a taxonspecific field detection methodology for pangolin species. The reliance on hunters' knowledge and their ability to extract large numbers of pangolins highlights the importance of applying traditional ecological knowledge (TEK) and the hunting experience of local people to the study and conservation of pangolins, and suggests that pangolins may not be as rare as field surveys alone might indicate.

Retrospective support for the notion of tapping hunters' knowledge of pangolins also came from the relationship between biologists' records and hunters' reports of the 2 pangolin species. Of the few field records obtained from ecological survey methods, Manis pentadactyla were more frequently recorded from signs of their presence, whilst sightings and camera-trap records were more common for $M$. javanica. This corresponds with the differences in population status and hunting methods derived from interviews, which reported that there were fewer $M$. pentadactyla and that these were more commonly found by tracking.

\section{Hunters' knowledge}

Caution is needed in interpreting data derived from hunter interviews, since respondents may have been reluctant to be honest about the magnitude of illegal activities. It is therefore likely that the results discussed here are conservative estimates of hunting prevalence and that the true intensity of anthropogenic pressure is higher than reported.

Hunters' reports correlated with the distribution maps of the 2 species in the 3 study areas, with Manis pentadactyla in CPNP, both species in KGKN and $M$. javanica in STNR. Knowledge of local names, and of the common tendency of hunters to refer to $M$. javanica as 2 different 'types' of pangolin, may benefit future surveys in peripheral areas of the 2 species' ranges. This tendency may explain some of the unconfirmed reports of $M$. pentadactyla in the southern provinces, since an interviewer may assume that a report of 2 pangolin types refers to 2 species rather than 1 . 
Interviewees believed the 2 species to be ecologically distinct, both in diet and in degree of terrestrial or arboreal lifestyle. These trends are unconfirmed, but were reported consistently, correlate with available species accounts and influence the hunting methods employed for each species. This suggests that these differences are at very least a useful guide for future studies of pangolin ecology.

\section{Hunting methods - species differences}

This research identified 4 main methods with which hunters catch pangolins in the 3 study sites: use of dogs, tracking signs, pangolin-specific traps and nonselective traps. Hunting with guns has diminished following the prohibition of private guns in the early 1990s (Sterling et al. 2006). Other methods of catching pangolins (e.g. spotlighting) seem to be both rare and opportunistic, and probably represent a relatively minor threat.

Dogs were considered by most hunters to be the most effective means by which to find pangolins, since a good hunting dog is capable of finding the scent of either species and following it to the burrow or hole in which the animal is sleeping. Dogs are used less than previously, however, for practical reasons unique to each area, as described above. A decline in the use of the most efficient means of hunting pangolins may have positive implications for their conservation, though this has probably occurred in parallel with increasing use of alternative hunting methods.

As a terrestrial species that digs conspicuous burrows in soil, Manis pentadactyla is mainly located by identifying an area in which a pangolin has been recently active and then searching for the occupied burrow. In contrast, M. javanica is mainly caught in snare traps, both pangolin-specific and non-selective. Traps are set at every hole hunters believe has been used by a pangolin and any alternative, unused holes are reportedly blocked to increase trap success rate. The practice of cutting down trees to capture the more arboreal $M$. javanica may also be reducing the number of tree hollows available for occupancy. Since M. javanica is thought to depend on hollows of large trees, particularly as sites for natal dens by the females ( $\operatorname{Lim} \& \mathrm{Ng} 2007$ ), harvesting them in this manner may mean habitat loss is acting concurrently to reduce populations.

Hunting pressure on Manis javanica is thus high, but the comparative ease with which $M$. pentadactyla is hunted, both with dogs and by tracking, suggests that the level of threat is higher for this latter species. At sites where the 2 species co-exist, populations of $M$. pentadactyla are likely to be more heavily diminished than those of M. javanica. This suggestion is supported by the lower population size of $M$. pentadactyla reported in KGKN and this has implications for the current Global Mammal Assessment review of IUCN Red List status.

\section{Hunting methods - site differences}

Inter-site variability is likely to be a confounding factor, with topographic and law enforcement characteristics affecting the relative prevalence of hunting practices in the study areas. For example, CPNP's steep limestone hills may prohibit the widespread use of long lines of snare traps, whereas the gentler slopes of KGKN and STNR are more conducive to their use. Similarly, the prevalence of hunting with dogs in KGKN is probably a consequence of less effective forest protection. An area's status as a national park (e.g. Cuc Phuong), a nature reserve (e.g. Song Thanh) or a state forest enterprise (e.g. Khe Net) is likely to affect the quality of control of illegal activities. Fear of Forest Protection Department rangers was the most commonly cited explanation for the decrease in dog use by hunters around CPNP, indicating that the extent of hunting activity may be reduced by effective law enforcement presence, as it has elsewhere in Asia (SFNC 2003, Lee et al. 2005, Corlett 2007).

\section{Studying pangolin ecology}

Although none of the previous surveys reviewed in this study specifically searched for pangolins within a given area, the low numbers of confirmed records from these surveys indicate that pangolins are largely missed by conventional biodiversity monitoring and require a genus-specific detection and census methodology. The scarcity of detailed and accurate data (e.g. altitude, habitat type) recorded with pangolin records is also a key problem. We recommend that, where possible, pangolin field detection and monitoring methods be integrated into general biodiversity surveys and also surveys targeting other taxa.

\section{Camera traps}

Since their development in the early 1980s, camera traps have become an important tool for monitoring rare, cryptic species in a wide range of environments (Cutler \& Swann 1999). The number of confirmed pangolin records has been augmented by camera-trap photographs, but this remains a financially costly method and frequently provides no confirmation of pangolin presence even in areas of known occurrence. Impor- 
tantly, a negative photo-trap result does not necessarily indicate the absence of a species from a study site, and successful photographs are too infrequent to be used as either a direct or comparative measure of population density. However, camera trapping may have an application as a non-intrusive means of studying pangolin behaviour and den use, once an individual has been found and its home range identified ( $\mathrm{Lim} \& \mathrm{Ng} 2007$ ).

\section{Line-transects}

Hunters reported using tracking to locate both Manis pentadactyla and $M$. javanica. The field sign most commonly reported as an indicator of pangolin presence was the diggings created by both species when searching for food. Pangolin burrows (diggings excavated deep enough for a pangolin to sleep in) were described as unmistakable for those of other species and as having a uniquely round entrance. Rodents' holes are significantly smaller and porcupines use natural holes and rock crevices rather than excavating their own burrows (Nowak 1999). Burrows, diggings and all other signs reported as useful could be used by field biologists. Sand traps placed at burrow entrances may be used to confirm pangolin occupancy. With appropriate training the presence of pangolins, particularly $M$. pentadactyla, may be recorded more effectively by survey teams in areas where populations still persist.

\section{Estimating population size}

Accurate estimation of the age of diggings and burrows could enable a surrogate measure of pangolin density to be developed, although occupant identity would need to be confirmed. True measures of population size would require knowledge of the rate of new burrow digging and also territory size, but comparative studies need only record number of active burrows per unit area in different habitats or sites. Similar approaches, based on relative burrow density, have been used to compare porcupine populations (Sidique \& Arshad 2004). For pangolins, such efforts would also be best invested during the rainy season, when these species may be more active (Allen 1938) and/or signs of their activity more easily visible.

\section{Sighting or capturing pangolins}

Currently, there is no established protocol for the rerelease of pangolins confiscated from the wildlife trade. Individuals are often released immediately into forest areas close to the point of confiscation, which may be some distance from the place of capture or even outside the animal's natural range. In addition to the potential for disease transmission, release at a suboptimal location may compromise an animal's chances of survival, as a consequence of unsuitable habitat or recapture into the trade (Sterling et al. 2006). For example, confiscated Manis javanica have been released into CPNP (S. Roberton pers. comm.), which this study suggests is outside of their natural range. A greater understanding of pangolin home range size and habitat utilisation will allow more informed decision-making for the placement of confiscated pangolins.

Training or confiscating dogs able to locate pangolins has potential application in their conservation, either as a direct method of determining population densities or as part of a protocol to capture pangolins for radio-tracking studies. Projects in New Zealand have demonstrated the potential of using 'conservation dogs' to locate elusive, endangered species (e.g. Robertson et al. 1999). Transferring such a method to Vietnam's forests may prove a viable option, although there may be practical difficulties associated with training dogs in areas of low pangolin density, as reported by hunters in KGKN.

The only method of capture reported not to injure the pangolin was placing a net over the entrance of an occupied burrow or hole. These can either be pegged out on the ground, whilst the trapper waits nearby, or incorporated into a snare mechanism that is triggered when the pangolin enters the net, lifting the animal off the ground. Though rarely used by hunters, due to their relatively high expense, such nets were commonly described as the only method of catching a pangolin that is guaranteed not to injure it. At a cost of US\$1.50 per net, this is an option that would be within the budget of most conservation field programs, and could be used in conjunction with net transmitters to allow multiple traps to be set and monitored simultaneously.

\section{Trade}

There was no significant difference in the current price of pangolins between the 3 sites. This study found that as populations of pangolins decline, their value to hunters is increasing at a rate greater than that of annual inflation. The large range of values reported for 2006 and 2007 (Fig. 6) is an artefact of hunters describing the last known price as 'current,' regardless of the date of sale, and so recent prices are almost certainly higher than indicated (reliable reports of US\$94 per kg, authors' pers. obs.). Prices of pangolins appear to be higher in Vietnam than in neighbouring countries (e.g. Cambodia: US\$45 per kg, C. Phallika pers. comm.; In- 
donesia: US\$17 per kg, D. Martyr pers. comm.), although a regional trade study would be required to confirm this. The lower prices per $\mathrm{kg}$ reported for larger-sized pangolins confirm observations in previous studies (Nooren \& Claridge 2001). This may reflect an attempt by traders to set an upper limit on the total price paid for a pangolin. However, a hunter may still gain several months' or a year's salary from a single animal, so it is unlikely that selling a pangolin will ever be an unprofitable enterprise (Sterling et al. 2006).

\section{CONCLUSION}

We suggest that the above recommendations for the study of pangolins may be of considerable benefit to field biologists and conservation programs in Vietnam and Southeast Asia. If pangolin populations are to persist, however, then law enforcement must also reduce the extent of the main threats through confiscation of hunting dogs, removal of snare lines or regulation of access to the forests. Such enforcement is critical if Vietnam's protected areas are to fulfil their purpose as effective conservation units. Of greatest significance was the wealth of knowledge and experience that we encountered amongst the interviewees during the course of this study. The enormous value of recruiting experienced local hunters was demonstrated for us during brief guided visits into the forest, during which we quickly began to recognise pangolins' field signs. Utilising the knowledge of local people may be equally successful for other taxa and in other locations.

Acknowledgements. We thank Dr. I. Barr, Dr. J. Gill, Prof. A. Grant, Dr. M. Hayward and Prof. A. Lovett for comments on the manuscript. This study was carried out in conjunction with the Carnivore and Pangolin Conservation Program, Cuc Phuong National Park. The following people and organisations assisted by making data available: IUCN, Hanoi; B. Long at WWF Vietnam; J. Pilgrim at BirdLife Indochina; S. Swan and B. Catarelli at FFI Vietnam; T. McCormack at the Turtle Conservation Program, Vietnam; and A. Olson at Conservation International, Cambodia. For hospitality and logistical support in the field, we are grateful to ENV, Hanoi; Mr. Vu of the Song Thanh Forest Protection Department, the Khe Net and Ke Go Forest Rangers and Mr. Khanh. P.N. was supported by a NERC studentship (number 3410625).

\section{LITERATURE CITED}

Allen GM (1938) The mammals of China and Mongolia. The American Museum of Natural History, New York

Anonymous (2005) Going, going, gone: the illegal trade in wildlife in east and southeast Asia. Environment and Social Development East Asia and Pacific Region Discussion Paper. The World Bank, Washington, DC

Baltzer MC, Dao NT, Shore RG (2001) Towards a vision for biodiversity conservation in the forests of the lower
Mekong ecoregion complex: technical annex. World Wildlife Fund, Hanoi

Bell D, Roberton S, Hunter PR (2004) Animal origins of SARS coronavirus: possible links with the international trade in small carnivores. Philos Trans R Soc B 359:1107-1114

Bennett EL, Milner-Gulland EJ, Bakarr M, Eves HE, Robinson JG, Wilkie DS (2002) Hunting the world's wildlife to extinction. Oryx 36:328-329

Bernard HR (2000) Social research methods - qualitative and quantitative approaches. Sage Publications, London

BirdLife (2003) Parc Ba Be/Na Hang-creating PAs for resource conservation using landscape ecology. BirdLife Indochina, Hanoi

BirdLife (2004) Parc Yok Don-creating PAs for resource conservation using landscape ecology. BirdLife Indochina, Hanoi

Care (2004) Biodiversity survey: U Minh Thuong National Park, Vietnam. U Minh Thuong National Park conservation and community development program (1998-2003). Agricultural Publishing House, Hanoi

CEPF (Critical Ecosystem Partnership Fund) (2005) Ecosystem profile: Indo-Burma hotspot, Indochina region. Available at: www.cepf.net/where_we_work/indoburma/ indoburma_info.xml (accessed September 2008)

CITES (Convention on International Trade in Endangered Species) (2007) CITES Appendices I, II and III. Available at: www.cites.org/eng/app/appendices.shtml (accessed July 2007)

Compton J, Le QH (1998) Borderline: an assessment of the wildlife trade in Vietnam. WWF Indochina Programme, Hanoi

Corbet GB, Hill JE (1992) The mammals of the Indomalayan region: a systematic review. Natural History Museum publications, Oxford University Press, Oxford

Corlett RT (2007) The impact of hunting on the mammalian fauna of tropical Asian forests. Biotropica 39:292-303

Cutler TL, Swann DE (1999) Using remote photography in wildlife ecology: a review. Wildl Soc Bull 27:571-581

Dang HH, Cao SV, Le CX (1995) A report on the survey for biological resources in Yok Don National Park, South Vietnam. IEBR, Hanoi

Dang DX, Do TH, Osborn T (2004) Biodiversity and socio-economic assessment of Da Teh State Forest Enterprise, Lam Dong Province, Vietnam. WWF Indochina Programme, Hanoi

Davies B (2005) Black market-inside the endangered species trade in Asia. Earth Aware Editions, San Rafael

Duckworth JW, Salter RE, Khounboline K (1999) Wildlife in Laos PDR: 1999 status report. IUCN, Vientiane

Ellis R (2005) Tiger bone and rhino horn - the destruction of wildlife for traditional Chinese medicine. Island Press, London

Emmett DA, Olsson A (2005) Biological surveys in the Central Cardamom Mountains. Conservation International Cambodia Program and Forestry Administration, Phnom Penh

Fa JE, Peres CA, Meeuwig J (2002) Bushmeat exploitation in tropical forests: an intercontinental comparison. Conserv Biol 16:232-237

FFI (Fauna and Flora International) (2005) Pu Luong Nature Reserve: biodiversity surveys of a key site for conservation. Fauna and Flora International, Hanoi

FFI (Fauna and Flora International) (2006) An assessment of mammal fauna: Khau Ca area. Fauna and Flora International, Hanoi

Frontier Vietnam (1994) Ba Na Nature Reserve: scientific report. Frontier Vietnam Environmental Research Report 3. Society for Environmental Exploration, Hanoi 
Frontier Vietnam (1996) Biological survey of Na Hang nature reserve, Tuyen Quang province, Vietnam. Part I: Ban Bung sector. Frontier Vietnam Environmental Research Report 8. Society for Environmental Exploration, Hanoi

Gaubert P, Antunes A (2005) Assessing the taxonomic status of the Palawan pangolin Manis culionensis (Pholidota) using discrete morphological characters. J Mammal 86: 1068-1074

Geissmann T, Dang NX, Lorimee N, Momberg F (2000) Vietnam primate conservation status review. Part 1. Gibbons. Fauna \& Flora International, Indochina Programme, Hanoi

Heath ME, Coulson IM (1997a) Home range size and distribution in a wild population of Cape pangolins, Manis temminckii, in north-west Zimbabwe. Afr J Ecol 35:94-109

Heath ME, Coulson IM (1997b) Preliminary studies on relocation of Cape pangolins Manis temminckii. S Afr J Wildl Res 27:51-56

Huntington HP (2000) Using traditional ecological knowledge in science: methods and applications. Ecol Appl 10: $1270-1274$

IUCN (International Union for Conservation of Nature) (2007) IUCN Red List of Threatened Species. Available at: www.redlist.org (accessed July 2007)

Kong K, Tan S (2002) A wildlife survey of Kirirom National Park, Cambodia. WCS Cambodia Program, Phnom Penh

Le DT (2004) Summary report of camera trapping programme. Pu Luong-Cuc Phuong Conservation Project. Fauna and Flora International, Hanoi

Le CX, Truong LV, Dang DT, Ho CT and others (1997a) A report of field surveys on biodiversity in Phong Nha Ke Bang forest (Quang Binh Province, central Vietnam). IEBR/FIPI/Forestry College/University of Vinh/WWF Indochina Programme. WWF Indochina Programme, Hanoi

Le CX, Pham AT, Duckworth JW, Vu TN, Lic V (1997b) A survey of large mammals in Dak Lak province, Vietnam. WWF/IUCN, Hanoi

Le TT, Eames JC, Nguyen TD, Furey NM and others (2004) Biodiversity report on the $\mathrm{Ba} \mathrm{Be} / \mathrm{Na}$ Hang Conservation Complex, Creating Protected Areas for Resource Conservation using Landscape Ecology (PARC) Project. Government of Vietnam (FPD)/UNOPS/UNDP/Scott Wilson Asia-Pacific, Hanoi

Lee RJ, Gorog AJ, Dwiyahreni A, Siwu S and others (2005) Wildlife trade and implications for law enforcement in Indonesia: a case study from North Sulawesi. Biol Conserv 123:477-488

Lim NTL, Ng PKL (2008) Home range, activity cycle and natal den usage of a female Sunda pangolin Manis javanica (Mammalia: Pholidota) in Singapore. Endang Species Res $4: 233-240$

Long B, Tuoc D (1999) A participatory conservation strategy for the Khe Bong Valley, Pu Mat NR. Fauna and Flora International, Hanoi

Lynam AJ, Round PD, Brockelman WY (2006) Status of birds and large mammals in Thailand's Dong Phayayen-Khao Yai Forest Complex. Biodiversity Research and Training (BRT) Program and Wildlife Conservation Society, Bangkok

Murphy D, Phan TD (2001) Mammal observations in Cat Tien National Park. WWF, Hanoi

Nadler T, Momberg F, Dang NX, Lorimee N (2003) Vietnam primate conservation status review 2002. Part 2. Leaf mon- keys. Frankfurt Zoological Society and Fauna \& Flora International Vietnam Programme, Hanoi

Neath N, Setha T (2001) A wildlife survey of Bokor National Park, Cambodia. Wildlife Conservation Society Cambodia Programme, Phnom Penh

Nooren H, Claridge G (2001) Wildlife trade in Laos: the end of the game. IUCN, Amsterdam

Nowak RM (1999) Walker's mammals of the world, Vol 2, 6th edn. John Hopkins University Press, Baltimore, MD

Roberton S (2007) The status and conservation of small carnivores in Vietnam. PhD thesis, University of East Anglia, Norwich

Roberton S, Thuong HV, Nguyen NN, Ho L and others (2004) The illegal wildlife trade in Quang Nam province: covert investigations by specially trained forest rangers. Wildlife law enforcement strengthening: Report No. 5. The Quang Nam Forest Protection Department and WWF Indochina, Hanoi

Robertson HA, Colbourne RM, Graham PJ, Miller PJ, Pierce RJ (1999) Survival of brown kiwi (Apteryx mantelli) exposed to brodifacoum poison in northland. NZ J Ecol 23:225-231

Round PD (1999) Avifaunal surveys of the Pu Mat Nature Reserve, Nghe An province, Vietnam 1998-1999. Vinh: Social Forestry and Nature Conservation in Nghe An Province, Hanoi

Salganik MJ, Heckathorn DD (2004) Sampling and estimation in hidden populations using respondent-driven sampling. Sociol Methodol 34:193-239

SFNC (Social Forestry and Nature Conservation) (2001) Pu Mat: biodiversity survey in a nature reserve of Vietnam. SFNC, Hanoi

SFNC (Social Forestry and Nature Conservation) (2003) Hunting and trading wildlife: an investigation into the wildlife trade in and around the Pu Mat National Park, Nghe An province, Vietnam. SFNC, Hanoi

Sidique MM, Arshad M (2004) Relative density of porcupine (Hystrix indica) population in forest plantation by food station transect method. Pak J Biol Sci 7:1745-1749

Sterling EJ, Hurley MM, Le MD (2006) Vietnam - a natural history. Yale University Press, New Haven, CT

Timmins RJ, Cuong TV (1999) An assessment of the conservation importance of the Huong Son (Annamite) forest, Ha Tinh province, Vietnam, based on the results of a field survey for large mammals and birds. Center for Biodiversity and Conservation at the American Museum of Natural History, New York

UNICEF (2007) UNICEF information by country, at a glance: Vietnam. Available at: www.unicef.org/infobycountry/ vietnam_statistics.html (accessed July 2007)

US Department of State (2007) Background note: Socialist Republic of Vietnam. Available at: www.state.gov/r/pa/ ei/bgn/4130.htm\#econ (accessed July 2007)

Vu TN, Nguyen DX, Nguyen HM (2005) Survey and assessment of the Cao Vit gibbon population. Fauna and Flora International, Hanoi

Walston J, Davidson P, Men S (2001) A wildlife survey of southern Mondulkiri province, Cambodia. Wildlife Conservation Society Cambodia Programme, Phnom Penh

WCS (1995) A wildlife and habitat survey of the area to be affected by the Theun-Hinboun hydropower project, Lao PDR. WCS, Vientiane

Wu SB, Liu NF, Ma GZ, Xu ZR, Chen H (2003) Habitat selection by Chinese pangolin (Manis pentadactyla) in winter in Dawuling Natural Reserve. Mammalia 67:493-501 